\title{
科尔沁沙地植被恢复系列上群落演替与 物种多样性的恢复动态
}

\author{
张继义 赵哈林 张铜会 赵学勇 \\ (中国科学院寒区旱区环境与工程研究所 兰州 730000)
}

\begin{abstract}
摘 要 通过对科尔沁沙地植被恢复系列上不同阶段的群落取样, 研究了植被恢复过程中群落物种组成、物种多 样性的变化过程。在演替时间分别为 1 年、 3 年、 5 年、 12 年、 20 年和 30 年的群落中 物种丰富度分别为 $7 、 11 、 17 、 14 、$ 28 和 30 种, 而物种多样性指数分别为 1.458 8、2.610 0、3.108 4、1.696 8、3.738 6、3.6396。在生活型结构上, 一年生 植物的种类数量占绝对优势, 但随着演替进展, 多年生植物的种类数量增加且单种植物的优势度超过了一年生植 物, 表明多年生植物在群落功能维持中占据重要地位。随演替进展, 来自不同科属的植物增加。藜科植物在演替 过程中种类数量较为稳定, 特别是在演替早期栳科植物占有很高的优势度。禾本科种类随演替进展不断增加, 且 在群落中的优势度逐渐上升。总体上,随演替进展群落种类组成与物种多样性增加, 群落生态优势度下降, 而均匀 度增加, 群落趋向稳定。
\end{abstract}

关键词 科尔沁沙地 植被恢复 群落 演替 物种多样性

\section{DYNAMICS OF SPECIES DIVERSITY OF COMMUNITIES IN RESTORATION PROCESSES IN HORQIN SANDY LAND}

\author{
ZHANG Ji-Yi ZHAO Ha-Lin ZHANG Tong-Hui and ZHAO Xue-Yong \\ ( Cold and Arid Regions Environmental and Engineering Research Institute, Chinese Academy of Sciences , Lanzhou 730000 ,China)
}

\begin{abstract}
In this paper species composition and species diversity of communities with different succession times were studied in restoration processes. Our results showed that species richness is $7,11,17,14,28$ and 30 in the communities, of which the succession time is $1,3,5,12,20$ and 30 years , while the species diversity index is $1.4588,2.6100,3.1084,1.6968,3.7386$ and 3.6396 respectively. For life form composition of all communities along the restoration succession series, annual herbaceous plants are dominant, but species number of perennials increases and the dominance of one species is more than that of annuals as succession proceeds. Species number of Chenopodiaceae is stable and their dominance in the community is high , especially in early successional stages. Species number of Gramineae increases continuously along the succession gradient and their importance in community also increases. Ecological dominance declines gradually, while community evenness increases progressively along with succession. In a relatively short time of 30 years the environment of sandy land shifted successfully from mobile sandy land to fixed sandy land, and species composition and community structure improved greatly. This research provided test and sample for the possibility of vegetation restoration under natural condition , as well as a practical pathway for the protection of biodiversity. The most important thing is to stop irrational use of land so that the natural ecological processes of vegetation recovery such as dispersal, inhabitation and propagation can be accomplished continually under stable environments.
\end{abstract}

Key words Horqin sandy land, Vegetation restoration , Community, Succession , Species diversity

生物多样性是人类生存与发展的生物基础。物 种多样性为人类提供了宝贵的生物资源, 具有重要 的经济价值。随着人类活动范围的扩大和资源利用 强度的加深, 全球各类生态系统不断受到各种破坏， 生境破碎化, 物种多样性加速丧失, 威胁到人类的可
持续发展。退化生态系统的恢复和生物多样性保护 得到世界各国的关注和普遍重视(马克平 ,1994;Bai et al. 2001)。

物种多样性是群落的重要特征, 物种多样性为 生态系统功能运行和维持提供了种源基础和支撑条 
件。任何生态系统或群落类型都有其物种多样性特 征,而这种特征是该生态系统功能维持的生物基础 (Grime , 1997 ,Tilman \& Downing , 1994)。因此, 深入 研究生物多样性与生态系统功能二者之间的关系就 成为一项基本的科学问题 (West, 1993 ;Johnson et $a l$. , 1996 ）对于退化生态系统功能的恢复和生物 多样性保护具有重要的理论意义和实践意义。

科尔沁沙地地处我国北方半干旱农牧交错带， 由于土地过圼和超载放牧导致植被大量破坏, 土地 荒漠化严重, 并严重制约着该区域社会经济的可持 续发展。因此植被恢复成为该区域退化生态系统重 建的重要步骤和主要任务。草原是该区域的典型地 带性稳定植被类型, 在植被恢复和土地荒漠化治理 以及畜牧业生产中具有重要的地位和作用。该区域 沙地生态系统有流动沙丘系统、半固定沙丘系统和 固定沙丘系统等类型, 与其相对应的植物群落则分 别为流动沙地沙米 (Agriophyllum squarrosum) 群落、半 固定沙地差巴嘎蓠 (Artemisia halodendron) 群落、固定 沙地粘隐子草 (Cleistogenes squarrosa) 群落等群落类 型 (赵哈林等, 2000)。深入研究生态系统恢复序列 上群落演替与物种多样性的变化, 对回答多样性与 生态系统功能之间的关系有重要的理论价值, 并对 认识该地区植被恢复的过程、促进退化生态系统功 能的重建具有重要的指导意义。

\section{1 研究方法}

\section{1 调查取样}

研究区位于科尔沁沙地中南部的奈曼旗中国科 学院奈曼沙漠化研究站境内。地理位置 $120^{\circ} 41^{\prime} \mathrm{E}$, $42^{\circ} 54^{\prime} \mathrm{N}$ 。该地区属半干旱气候, 年平均降水量 366 $\mathrm{mm}$, 年蒸发量 $1935 \mathrm{~mm}$, 年均气温 $6.5{ }^{\circ} \mathrm{C}, 1$ 月平均 气温 $-12.7{ }^{\circ} \mathrm{C}, 7$ 月平均气温 $23.7{ }^{\circ} \mathrm{C}, \geqslant 10{ }^{\circ} \mathrm{C}$ 积温 $3000{ }^{\circ} \mathrm{C}$ 以上, 无霜期 $150 \mathrm{~d}$ 。土壤类型为沙质栗钙 土 经破坏后则退化为流动风沙土, 沙土基质分布广 泛，风沙活动强烈(赵哈林等，2000)。

由于沙土的干燥疏松和干旱多风等气候条件的 影响，使得该地区在过度放牧和过星等人为不合理 利用的情况下, 植被遭受破坏, 土地沙化, 成为流动 沙丘。但是由于沙土良好的水分储藏性能, 在大量 天然种源存在的情况下和禁止放牧、禁止开垦等良 好的保护措施下, 也存在着植被快速建立并向稳定 植被类型演替的可能。

以流动沙丘先锋植物——沙米群落的建立为植 被恢复的起点, 沙地生态系统恢复的过程伴随着植
被发育和群落演替, 也是松散沙粒基质的流动性不 断降低、沙地逐渐得到固定的过程。由流动沙丘到 半固定沙丘、再到固定沙丘，生态系统恢复的每一阶 段都发育着典型的群落类型, 沙地环境的变化与群 落类型的演替变化相一致和相对应 (李胜功等, 1997）,因此把沙地环境从流动沙丘到半固定沙丘、 再到固定沙丘的几个明显的阶段作为生态系统恢复 阶段。群落演替时间的确定则是从进行围封、完全 停止干扰后开始计算。

该文用时-空替代的方法，在野外选取分别处于 流动沙丘、半固定沙丘和固定沙丘等不同恢复阶段 的 6 个演替时间互不相等的典型群落样地进行调 查。所选的 6 个群落样地其围封历史清楚, 围封期 间保护较好, 基本未受放牧和人为破坏等干扰。从 进行围封停止干扰后开始算起,6个群落的演替时 间分别为 1 年、 3 年、 5 年、 12 年、 20 年和 30 年。从 沙地环境状况判断其所处的恢复阶段, 1年和 3 年 的群落处于流动沙地阶段 ,5年和 12 年的群落处于 半固定沙地阶段, 20 和 30 年的群落处于固定沙地 阶段。

每个群落类型样地上取互相平行的 3 条样带, 样带长 $600 \mathrm{~m}$ 样带间距 $200 \mathrm{~m}$ 样带上每隔 $20 \mathrm{~m}$ 取 样方一个, 样方面积按照草本植被常规调查方法取 $1 \mathrm{~m}^{2}$ 。每群落类型取样方 60 个, 共取样 360 个。样 方中调查各植物种类的密度、高度和盖度。对于草 本植物来说, 其个体矮小, 个体数量变化比较大, 通 常用密度、高度和盖度三者相结合的重要值作为指 标能较好地代表和反映该种群在群落中的实际情 况, 本文以重要值 (优势度) 作为数量指标进行分析。

\section{2 分析方法}

\subsection{1 物种重要值和物种优势度}

$I V=$ 相对密度 + 相对高度 + 相对盖度

$D V=I V / 300$

$I V$ 指物种的重要值, $D V$ 指物种的优势度。

\subsection{2 多样性指数}

采用 Shannon-Wiener 指数测定物种多样性 (马 克平，1994）:

$S W=3.3219\left(\log N-\left(\sum n_{i} \log n_{i}\right) 1 / N\right)$

其中 $S W$ 是 Shannon-Wiener 多样性指数, $N$ 为物种 总个体数, $n_{i}$ 为物种 $i$ 的个体数。文中 $n_{i}$ 用物种优 势度代替。

\subsection{3 群落生态优势度}

采用 Simpson 指数测定生态优势度 (Pielou， 1977) : 
$S N=\sum n_{i}\left(n_{i}-1\right) / N(N-1)$

其中 $S N$ 为 Simpson 指数, $n_{i} 、 N$ 的含义同上式。

\section{2 .4 群落均匀度}

采用 $P W$ 指数测定群落均匀度 (彭少麟等, $1983 ; 1998)$ :

$P W=\left(\log N-(1 / N) \sum_{i=1}^{n} n_{i} \log n_{i}\right) /\{\log N-(1 /$

$N)[\alpha(s-\beta) \log \alpha+\beta(\alpha+1) \log (\alpha+1)]\}$

其中 $s$ 为群落中的物种数, $N$ 为所有物种的个体总 数, $n_{i}$ 为第 $i$ 种的个体数, $\beta$ 是 $N$ 被 $s$ 整除以后的余 数 $(0 \leqslant \beta<n), \alpha=(N-\beta) / s$ 。

\subsection{5 群落相似性系数}

采用 Sorensen 相似性指数来计算群落的相似 度 :

$$
C=Z_{j} /(a+b)
$$

其中 $Z_{j}$ 为两个群落的共有种在各群落中重要值的 总和, $a$ 和 $b$ 分别是两个群落中所有种重要值的总 和。

\section{2 研究结果}

\section{1 植被恢复系列上群落物种组成及其优势度 \\ 从表 1 可以看出, 在沙地生态系统恢复系列上， 伴随植被发育和群落演替过程物种丰富度逐渐增}

表 1 植被恢复系列上群落种类组成及物种优势度

Table 1 Species composition and dominance of communities in restoration succession processes

\begin{tabular}{|c|c|c|c|c|c|c|}
\hline \multirow{3}{*}{ 物种 Species } & \multicolumn{6}{|c|}{ 恢复阶段 Restoration stage } \\
\hline & \multicolumn{2}{|c|}{$\begin{array}{c}\text { 流动沙地 } \\
\text { Mobile sandy dune }\end{array}$} & \multicolumn{2}{|c|}{$\begin{array}{c}\text { 半固定沙地 } \\
\text { Semi-fixed sandy dune }\end{array}$} & \multicolumn{2}{|c|}{$\begin{array}{l}\text { 固定沙地 } \\
\text { Fixed sandy dune }\end{array}$} \\
\hline & $\begin{array}{c}1 \text { 年 } \\
\text { One year }\end{array}$ & $\begin{array}{c}3 \text { 年 } \\
\text { Three years }\end{array}$ & $\begin{array}{c}5 \text { 年 } \\
\text { Five years }\end{array}$ & $\begin{array}{c}12 \text { 年 } \\
\text { Twelve years }\end{array}$ & $\begin{array}{c}20 \text { 年 } \\
\text { Twenty years }\end{array}$ & $\begin{array}{c}30 \text { 年 } \\
\text { Thirty years }\end{array}$ \\
\hline 沙米 Agriophyllum squarrosum & 68.0750 & 28.0210 & 0.6920 & 0 & 0 & 0 \\
\hline 狗尾草 Setaria viridis & 16.9140 & 30.8140 & 12.9190 & 3.7192 & 10.5010 & 8.2411 \\
\hline 雾冰藜 Bassia dasyphylla & 9.0568 & 18.3140 & 32.9100 & 4.8300 & 6.2557 & 0.9625 \\
\hline 猪毛菜 Salsola collina & 3.3936 & 5.5536 & 16.4170 & 4.0933 & 21.0140 & 6.3938 \\
\hline 长穗虫实 Corispermum elongatum & 0.1872 & 1.2337 & 4.4530 & 3.1936 & 4.8323 & 2.9782 \\
\hline 地梢瓜 Cynanchum thesioides & 1.4311 & 0 & 5.0700 & 1.3894 & 3.4089 & 0.1511 \\
\hline 差巴嘎蒿 Artemisia halodendron & 0.9430 & 3.7559 & 7.5433 & 73.6030 & 13.4070 & 0 \\
\hline 马唐 Digitaria sanguinalis & 0 & 2.4218 & 4. 1212 & 0.4923 & 0.6052 & 0.4877 \\
\hline 苦苣菜 Sonchus oleraceus & 0 & 3.3367 & 2.6900 & 1.4410 & 2.6504 & 0 \\
\hline 画眉草 Eragrostis pilosa & 0 & 0 & 0.3865 & 0.2647 & 3.4081 & 10.4210 \\
\hline 三芒草 Aristida adscensionis & 0 & 0 & 1.1330 & 0.9832 & 11.7430 & 9.6767 \\
\hline 虎尾草 Chloris virgata & 0 & 0 & 0 & 0 & 0.7060 & 12.2590 \\
\hline 溪藜草 Cenchrus calyculatus & 0 & 0 & 2.1183 & 0 & 0 & 0 \\
\hline 达乌里胡枝子 Lespedeza davurica & 0 & 0.7998 & 2.1686 & 1.9363 & 0.7754 & 2.8981 \\
\hline 扁宿豆 Melissitus ruthenicus & 0 & 0 & 1.6840 & 0 & 2.6356 & 0.4298 \\
\hline 砂引草 Messerschmidia sibirica & 0 & 4.0805 & 1.8338 & 0 & 0 & 0 \\
\hline 地锦 Euphorbia humifusa & 0 & 0 & 1.8900 & 0.4610 & 6.4703 & 0.2227 \\
\hline 白草 Pennisetum centrasiaticum & 0 & 0 & 0 & 0.3967 & 1.2946 & 1.2571 \\
\hline 赖草 Leymus secalinus & 0 & 0 & 0 & 3.1952 & 0.4167 & 0.0429 \\
\hline 乳浆大戟 Euphorbia esula & 0 & 0 & 0 & 0 & 0.2288 & 0.1054 \\
\hline 冷蒿 Artemisia frigida & 0 & 0 & 0 & 0 & 1.9633 & 1.6448 \\
\hline 狭叶米口袋 Gueldenstaedtia stenophylla & 0 & 0 & 0 & 0 & 0.0716 & 0 \\
\hline 芦苇 Phragmites communis & 0 & 0 & 0 & 0 & 0.9235 & 0.4574 \\
\hline 展枝唐松草 Thalictrum squarrosum & 0 & 0 & 0 & 0 & 0.5857 & 0.3560 \\
\hline 鸡眼草 Kummerowia striata & 0 & 0 & 0 & 0 & 0 & 0.0568 \\
\hline 山葱 Allium scenescens & 0 & 0 & 0 & 0 & 0.2538 & 0.8990 \\
\hline 寸苔草 Carex duriuscula & 0 & 0 & 0 & 0 & 0 & 0.2562 \\
\hline 鹤闽 Lappula echinata & 0 & 0 & 0 & 0 & 0 & 0.6439 \\
\hline 白山䔡 Olgaea leucophylla & 0 & 0 & 0 & 0 & 0.0507 & 0.0172 \\
\hline 砂蓝刺头 Echinops gmelini & 0 & 0 & 0 & 0 & 0 & 0.0213 \\
\hline 防风 Saposhnikovia divaricata & 0 & 0 & 0 & 0 & 0.1415 & 0.6554 \\
\hline 二裂委陵菜 Potentilla bifurca & 0 & 0 & 0 & 0 & 0 & 0.7477 \\
\hline 䓡藜 Tribulus terrestris & 0 & 1.6690 & 0 & 0 & 0.0588 & 3.9871 \\
\hline 灰绿藜 Chenopodium glaucum & 0 & 0 & 0 & 0 & 0.6874 & 6.8538 \\
\hline 黄蒿 Artemisia scoparia & 0 & 0 & 1.9708 & 0 & 0.8802 & 2.8504 \\
\hline 䊁隐子草 Cleistogenes squarrosa & 0 & 0 & 0 & 0 & 4.0304 & 24.0280 \\
\hline 总种数 Sum of species & 7 & 11 & 17 & 14 & 28 & 30 \\
\hline
\end{tabular}


加 种群优势度在各群落中有起伏 ,但总体上种群优 势度明显, 少数物种贡献了群落生态功能的大部分。 优势物种更替明显，不同物种在不同演替时间的群 落中成为优势度最大的建群种，如在演替时间为 1 年、 3 年、 5 年、 12 年、 20 年和 30 年的序列上, 对应的 优势度最大的物种分别是沙米、狗尾草 (Setaria viridis)、雾冰藜 (Bassia dasyphylla)、差巴嘎葶、猪毛菜 ( Salsola collina)、䊁隐子草。

\section{2 物种的生活型结构}

从生活型组成看 (表 2), 在恢复系列上群落组 成中一年生草本植物占优势。随着演替的进行, 生 活型组成趋于多样化，多年生植物的种类不断增加， 在半固定沙地 (12 年)和固定沙地 (30 年)阶段, 多年 生植物的单种最大优势度明显超过一年生植物，表 明多年生植物虽然种类数量次于一年生植物, 但对 群落生态功能的维持起主要作用, 对群落环境演变 和植被演替居主导地位。多年生植物具有比一年生 植物更强的抵抗环境扰动和保持种群稳定的能力, 物种生活型组成上的这种变化反映植被恢复过程生 态系统结构与功能的变化特征, 群落结构趋于稳定， 生态功能增强。

\section{3 物种的科属组成}

分类上来自不同科属的植物表示形态特征上的 差异,也可能预示着差异多样的生态属性。从表 3 可以看出，在植被恢复序列上来自不同分类群的物 种增加，群落组成更加复杂化和多样化。来自不同 科属的植物种数及其在群落中的作用随着恢复阶段 和群落演替时间的变化而变化,栳科植物的数量较 为稳定, 特别是在群落发育的早期占有很高的优势 度, 说明僽科植物对群落演替早期严酷环境较强的 适应能力和对植被恢复的重要性。其次为菊科植 物 种类数量较少, 但在演替时间为 12 年的群落中 占有很高的优势度, 这主要是指半固定沙地的差巴 嘎茣群落。禾本科植物随着演替的进展种类数量不 断增加，优势度上升，其在群落中的作用和功能逐渐 重要。在 30 年时的固定沙地群落中禾本科植物占 有最大的优势度, 成为群落组成的主体和群落功能 的主导者。

\section{4 群落物种多样性变化}

全面衡量物种多样性需要从物种丰富度、均匀 度和生态优势度 3 个方面进行比较，它们都从不同 的角度反映群落物种组成结构水平，三者具有一定 的联系 (Kvalseth, 1991)。从物种多样性指数 (Shannon-Wiener 指数)的计算可以看出 (表4)，在演

表 2 植被恢复系列上群落种类组成的生活型结构

Table 2 Lifeform composition of species of communities along the restoration succession serial

\begin{tabular}{|c|c|c|c|c|c|c|c|c|c|c|}
\hline \multirow{2}{*}{$\begin{array}{c}\text { 演替时间 } \\
\text { Succession time (a) }\end{array}$} & \multicolumn{2}{|c|}{$\begin{array}{c}\text { 一年生草本植物 } \\
\text { Annual herbaceous } \\
\text { plants }\end{array}$} & \multicolumn{2}{|c|}{$\begin{array}{c}\text { 二年生草本植物 } \\
\text { Biennial herbaceous } \\
\text { plants }\end{array}$} & \multicolumn{2}{|c|}{$\begin{array}{c}\text { 多年生草本植物 } \\
\text { Perennial herbaceous } \\
\text { plants }\end{array}$} & \multicolumn{2}{|c|}{$\begin{array}{c}\text { 半灌木 } \\
\text { Semi-shrubs }\end{array}$} & \multicolumn{2}{|c|}{$\begin{array}{c}\text { 小半灌木 } \\
\text { Subsemi-shrubs }\end{array}$} \\
\hline & $\begin{array}{c}\text { 种数 } \\
\mathrm{Ns}\end{array}$ & $\begin{array}{c}\text { 优势度 } \\
\text { Ds }\end{array}$ & $\begin{array}{l}\text { 种数 } \\
\mathrm{Ns}\end{array}$ & $\begin{array}{c}\text { 优势度 } \\
\text { Ds }\end{array}$ & $\begin{array}{c}\text { 种数 } \\
\text { Ns }\end{array}$ & $\begin{array}{c}\text { 优势度 } \\
\text { Ds }\end{array}$ & $\begin{array}{l}\text { 种数 } \\
\text { Ns }\end{array}$ & $\begin{array}{c}\text { 优势度 } \\
\text { Ds }\end{array}$ & $\begin{array}{l}\text { 种数 } \\
\text { Ns }\end{array}$ & $\begin{array}{c}\text { 优势度 } \\
\text { Ds }\end{array}$ \\
\hline 1 & 6 & 99.06 & & & & & 1 & 0.94 & & \\
\hline 3 & 8 & 92.11 & & & 1 & 3.34 & 1 & 3.76 & 1 & 0.80 \\
\hline 5 & 12 & 83.94 & 1 & 1.97 & 2 & 4.37 & 1 & 7.54 & 1 & 2.17 \\
\hline 12 & 9 & 19.43 & & & 3 & 5.03 & 1 & 73.60 & 1 & 1.94 \\
\hline 20 & 17 & 70.77 & 1 & 0.88 & 7 & 12.21 & 1 & 13.41 & 2 & 2.74 \\
\hline 30 & 19 & 64.49 & 1 & 2.85 & 8 & 28.12 & & & 2 & 4.54 \\
\hline
\end{tabular}

Ns : Number of species Ds : Dominance of species

表 3 植被恢复系列上群落种类组成的分科结构

Table 3 Family structure of species of communities in restoration succession processes

\begin{tabular}{|c|c|c|c|c|c|c|c|c|c|c|c|c|c|c|}
\hline \multirow{2}{*}{$\begin{array}{c}\text { 演替时间 } \\
\text { Succession } \\
\text { time (a) }\end{array}$} & \multirow{2}{*}{$\begin{array}{c}\text { 总属数 } \\
\text { Number of } \\
\text { genera }\end{array}$} & \multirow{2}{*}{$\begin{array}{l}\text { 总科数 } \\
\text { Number of } \\
\text { families }\end{array}$} & \multicolumn{3}{|c|}{ 藜科 Chenopodiaceae } & \multicolumn{3}{|c|}{ 菊科 Compositae } & \multicolumn{3}{|c|}{ 禾本科 Gramineae } & \multicolumn{3}{|c|}{ 豆科 Leguminosae } \\
\hline & & & $\begin{array}{c}\text { 属数 } \\
\mathrm{Ng}\end{array}$ & $\begin{array}{c}\text { 种数 } \\
\text { Ns }\end{array}$ & $\begin{array}{c}\text { 优势度 } \\
\text { Ds }\end{array}$ & $\begin{array}{c}\text { 属数 } \\
\mathrm{Ng}\end{array}$ & $\begin{array}{c}\text { 种数 } \\
\text { Ns }\end{array}$ & $\begin{array}{c}\text { 优势度 } \\
\text { Ds }\end{array}$ & $\begin{array}{c}\text { 属数 } \\
\mathrm{Ng}\end{array}$ & $\begin{array}{c}\text { 种数 } \\
\text { Ns }\end{array}$ & $\begin{array}{c}\text { 优势度 } \\
\text { Ds }\end{array}$ & $\begin{array}{c}\text { 属数 } \\
\mathrm{Ng}\end{array}$ & $\begin{array}{c}\text { 种数 } \\
\text { Ns }\end{array}$ & $\begin{array}{c}\text { 优势度 } \\
\text { Ds }\end{array}$ \\
\hline 1 & 7 & 4 & 4 & 4 & 80.71 & 1 & 1 & 0.94 & 1 & 1 & 16.91 & - & - & - \\
\hline 3 & 11 & 6 & 4 & 4 & 53.12 & 2 & 2 & 7.09 & 2 & 2 & 33.24 & 1 & 1 & 0.80 \\
\hline 5 & 16 & 7 & 4 & 4 & 54.47 & 3 & 2 & 9.51 & 5 & 5 & 20.29 & 2 & 2 & 3.85 \\
\hline 12 & 14 & 6 & 3 & 3 & 12.12 & 2 & 2 & 75.04 & 6 & 6 & 8.56 & 1 & 1 & 1.94 \\
\hline 20 & 26 & 10 & 4 & 4 & 32.79 & 4 & 3 & 18.90 & 9 & 9 & 33.02 & 3 & 3 & 3.48 \\
\hline 30 & 29 & 12 & 4 & 4 & 17.19 & 4 & 3 & 4.50 & 9 & 9 & 66.38 & 3 & 3 & 0.43 \\
\hline
\end{tabular}


替的早期，物种多样性随着演替而增加。流动沙地 上一年生的沙米群落是植被恢复的起点, 其物种多 样性最低, 演替时间为 3 年和 5 年时, Shannon-Wiener 指数持续递增。而演替到 12 年时, 物种多样性指数 出现了较大幅度的下降, 其原因可能是群落较高的 生态优势度所造成。克隆植物的竞争作用可以导致 群落的物种多样性下降(宋明华等, 2002) ,作为一种 密集型克隆植物, 半固定沙地上差巴嘎蒿种群的优 势度非常高, 在沙地上的适应能力使其具有极强的 空间侵占能力和对其它物种的竞争作用，结果是群 落的生态优势度上升, 而多样性水平下降。在固定 沙地阶段 (20 年和 30 年) 差巴嘎蒿种群的衰退和沙 地环境的变化, 提高了其它物种的竞争能力, 为其它 物种的侵入创造了条件, 新的物种大量侵入。群落 的物种多样性再次升高, 并达到恢复序列上的最高 点。

与物种多样性的变化相对应, 群落生态优势度 在演替早期随物种多样性的升高而下降, 在演替到
12 年时群落生态优势度则上升到最高值, 以后又随 演替进展和物种多样性的升高而下降。群落均匀度 与物种多样性的变化相一致 到演替至 12 年半固定 沙地差巴嘎蕎群落时, 群落均匀度下降, 以后又随演 替进展而增加, 并保持稳定。研究结果表明, 在沙地 生态系统恢复系列上, 群落的物种多样性指数和均 匀度随演替进展而升高，并保持相对稳定，群落生态 优势度则随演替进展而下降, 说明随着演替进展, 群 落的组成结构趋向均匀和稳定。

\section{5 群落相似性分析}

相似性系数的计算结果表明 (表 5),,每一群落 类型总是与其下一阶段最邻近的群落具有最高的相 似度 相似系数在 0.9 左右。随着演替进展, 群落之 间的演替时间越长, 则相似性系数越低, 表明群落物 种组成差异不断增加，群落之间的生态距离变远。 相似性系数的这种变化清楚地表明了植被恢复系列 上和群落演替过程中物种组成结构的递进性和渐变 性。

表 4 植被恢复系列上群落的物种多样性、生态优势度与均匀度

Table 4 The species diversity , ecological dominance and evenness of communities in restoration succession processes

\begin{tabular}{|c|c|c|c|c|c|c|}
\hline & \multicolumn{6}{|c|}{ 演替时间 Succession time (a) } \\
\hline & \multicolumn{2}{|c|}{ 流动沙丘 Mobile sandy dune } & \multicolumn{2}{|c|}{ 半固定沙丘 Semi-fixed sandy dune } & \multicolumn{2}{|c|}{ 固定沙丘 Fixed sandy dune } \\
\hline & 1 & 3 & 5 & 12 & 20 & 30 \\
\hline 物种多样性 Species diversity & 1.4588 & 2.6100 & 3.1084 & 1.6968 & 3.7386 & 3.6396 \\
\hline $\begin{array}{l}\text { 生态优势度 } \\
\text { Ecological dominance }\end{array}$ & 0.4966 & 0.2074 & 0.1691 & 0.5456 & 0.0947 & 0.1046 \\
\hline 均匀度 Community evenness & 0.5198 & 0.7546 & 0.7609 & 0.4459 & 0.7800 & 0.7439 \\
\hline
\end{tabular}

表 5 植被恢复系列上群落的相似性系数

Table 5 The similarity of communities in restoration succession processes

\begin{tabular}{|c|c|c|c|c|c|c|}
\hline \multirow{3}{*}{$\begin{array}{c}\text { 演替时间 } \\
\text { Succession time (a) }\end{array}$} & \multicolumn{6}{|c|}{ 恢复阶段 Succcession stage } \\
\hline & \multicolumn{2}{|c|}{ 流动沙地 Mobile sandy dune } & \multicolumn{2}{|c|}{ 半固定沙地 Semi-fixed sandy dune } & \multicolumn{2}{|c|}{ 固定沙地 Fixed sandy dune } \\
\hline & 1 & 3 & 5 & 12 & 20 & 30 \\
\hline 1 & 1 & 0.9313 & 0.9000 & 0.6092 & 0.4567 & 0.1549 \\
\hline 3 & & 1 & 0.9204 & 0.7977 & 0.6400 & 0.4257 \\
\hline 5 & & & 1 & 0.9405 & 0.8981 & 0.6742 \\
\hline 12 & & & & 1 & 0.9204 & 0.3434 \\
\hline 20 & & & & & 1 & 0.9107 \\
\hline 30 & & & & & & 1 \\
\hline
\end{tabular}

\section{3 讨 论}

沙地植被恢复梯度上物种组成与群落演替的这 种动态变化格局反映了生态系统恢复过程群落环境 的变化和生物多样性对这种变化的响应过程。生态 系统恢复过程中由于植被发育使土壤基质的稳定性
提高，更多物种的繁殖体得以散布和定居，这是物种 多样性恢复的条件之一。细土物质沉积和有机质积 累使土壤肥力和养分条件改善，从而允许更多物种 的发育和成功繁殖, 这是物种多样性恢复的条件之 二。研究结果提供了在区域物种库影响下物种多样 性恢复的自然进程, 这基本上是两个过程作用的结 
果 :1)时间积累效应，一定的物种要进入某一环境空 间并建立种群,需要有足够的时间成功地完成其繁 殖体从种源地到目标空间的传播、散布和在目标空 间的定居、繁殖过程, 这一过程进行的速率直接影响 物种多样性恢复的进度, 毫无疑问, 随着时间积累将 有越来越多的物种完成这一生态过程而成为群落的 组成物种。这一过程进行的速率取决于群落斑块面 积的大小、物种的生态特性和种源距离的远近等生 态因素。2)群落建立后群落-环境相互作用下群落 环境的演变,总体环境的改善为更多物种的生存和 繁衍提供了可能,同时，不同的环境可能适合于一些 物种而不适合于另外一些物种。此外,生物过程(种 间相互作用)也影响群落物种多样性, 如某一种群过 高的优势度所产生的竞争排除作用有可能导致群落 物种多样性的下降。

物种的生态特性决定其在群落中的优势度。流 动沙地是植被退化的极点, 在流动沙地上植被的恢 复主要有两点困难 (李胜功等, 1997) :一是沙土基 质的不稳定性和干燥多风气候条件的耦合使得大部 分植物的繁殖体难以入侵定居;二是极端贫乏的养 分条件不足以维持植被的发育。沙米是流动沙地的 先锋植物, 沙米以其特殊的适应机制能够在流沙上 成功定居, 如小而扁平的种子能够滞留于沙土中不 致受风吹滚动而丢失, 种子遇水后胚根首先以极快 的速度生长，下扎于沙土中，使植物体牢牢固着于沙 土中 抵御风蚀的侵害。沙米还是一种寡养型植物， 常常在流动沙丘上成片密集生长。沙米以其特殊的 生理生态特性成为流动沙地的先锋植物, 在群落中 的优势度最大。

从物种多样性与生态系统功能的关系来看, 植 被恢复梯度上优势种在群落中的地位和作用对群落 演替和环境演变起主导作用, 各个物种在群落或生 态系统中的作用并非是等同的，某些优势种的生态 功能对群落的作用是不可替代的, 在严重荒漠化及 干旱风沙等生态脆弱地区和严酷环境条件下，生态 系统功能的维持强烈地依赖于某些主要种群的作用 (Walker, 1992; Lawton \& Brown ,1993)。次要种的存 在具有填补空白斑块的作用, 使群落对环境和资源 的利用尽可能达到最大。人们总是希望证明生态系 统功能随着物种多样性的增加而增强, 从我们的研 究结果看并不存在这种线形关系。生态系统功能与 物种数量的多少没有直接关系, 而是强烈地依赖于 某些主要种群的作用。应该看到，生物多样性对生 态系统功能的价值在于它提供了各种千差万别的不
同生态特性的物种，从而有可能使某一生态特性的 物种在特定的群落环境中成为优势种, 并成为群落 生态功能的主要维持者。

在植被恢复过程中, 物种多样性最高的群落并 非是最稳定和演替历史最长的群落。演替时间为 20 年的群落物种多样性最高, 它是半固定沙地差巴 嘎蓠群落向固定沙地糙隐子草群落演替过渡的中间 类型。说明阶段性优势群落类型之间交错过渡的中 间类型往往多样性最高, 而这些群落从稳定性上说 是短暂过渡的类型, 存在着向下一个更稳定类型的 快速演替和过渡。

生物多样性与生态系统功能的关系非常复杂 (吴彦等,2001)。对于生态系统功能的维持来说， 更多地应该看群落或生态系统由哪些物种组成, 以 及物种的特性, 而不是简单的物种数量的多少 (赵平 等, 2001)。在植被恢复和退化生态系统功能恢复 的实践中, 盲目地将一些物种结合在一起的做法是 无益的。安排什么样的物种以及安排多少物种决定 于环境条件、物种特性以及二者之间的适合程度。

\section{4 结 论}

在 30 年的时间内沙地环境实现了从极端退化 的流动沙地到固定沙地的转化, 群落环境发生了显 著的变化, 群落物种丰富度达到了一个较高的水平。 物种多样性这种较快的恢复进度为自然状态下植被 恢复的可能性和物种多样性保护的途径提供了范例 和验证。对于由人为不合理利用造成的生态系统退 化和物种多样性丧失, 首要的是停止不合理的土地 利用方式, 解决人与生态环境的极端矛盾状态, 使物 种的传播、散布、定居和繁殖等生态过程得以在稳定 的环境下进行, 植被就能得到恢复, 物种多样性就能 最大程度地得到保护。

物种多样性的恢复与群落环境的演变密切相 关, 群落环境的演变是物种多样性恢复的基础。物 种多样性作为群落的基本特征, 既表征群落的组成 结构, 也是对环境状况的指示。在科尔沁沙地植被 恢复过程中, 每一群落对环境的改造都对下一阶段 群落的形成和物种侵入创造了条件。一定的群落环 境对应着一定的物种多样性水平，严酷环境条件下 总是能够支持较少的物种, 而环境条件的改善则允 许更多物种的共存。因此,一定条件下的物种多样 性与该条件下的环境容量有关。生物多样性可以作 为群落或生态系统发育程度和健康状况的表征，但 生物多样性与生态系统功能之间不存在线形关系。 


\section{参 考 文 献}

Bai, Y. F., L. H. Li, J. H. Huang \& Z. Z. Chen. 2001. The influence of plant diversity and functional composition on ecosystem stability of four Stipa communities in the Inner Mongolia Plateau. Acta Botanica Sinica(植物学报), 43: $280 \sim 287$.

Grime, J. P. 1997. Biodiversity and ecosystem function: the debate deepens. Science, 277: 1260 1261 .

Johnson, K. H., K. A. Vogt, H. J. Clark, O. J. Schmitz \& D. J. Vogt. 1996. Biodiversity and the productivity and stability of ecosystems. Trends in Ecological Evolution, 11: $372 \sim 377$.

Kvalseth, T. O. 1991. Note on biological diversity, evenness, and homogeneity measures. Oikos, 62: 123 127 .

Lawton, J. H. \& V. K. Brown. 1993. Redundency in ecosystems. In: Schulze, E. D. \& H. A. Money eds. Biodiversity and ecosystem function. New York: Springer-Verlag. 225 270 .

Li, S. G. (李胜功), A. F. Zhao (赵爱芬) \& X. L. Chang (常学礼). 1997. Several problems about vegetation succession of Horqin sandy land. Journal of Desert Research (中国沙漠), 17 (Suppl. 1) : $25 \sim 32$. (in Chinese with English abstract)

Ma, K. P. (马克平) . 1994. The methods of measuring community diversity. I. Measurement of $\alpha$ diversity. Chinese Biodiversity (生物多样性), 2: 162 168. (in Chinese with English abstract)

Peng, S. L. (彭少麟) \& B. S. Wang (王伯荪). 1983. Analysis on the forest communities of Dinghushan. I. Species diversity. Ecology Science (生态科学), 1: 11 17. (in Chinese with English abstract)

Peng, S. L. (彭少麟)，W. Fang (方炜) \& H. Ren (任海). 1998. The dynamics on organization in the successional process of Dinghushan Cryptocarya community. Acta Phytoecologica Sinica
(植物生态学报), 22: $245 \sim 249$. (in Chinese with English abstract)

Pielou, E. C. 1977. An introduction of mathematical ecology. New York: Willey.

Song, M. H. (宋明华), Y. F. Chen (陈玉福) \& M. Dong (董 鸣). 2002. Clonal plants along the sandy hill-slope in Ordos plateau and relation of their importance to plant species diversity. Acta Phytoecologica Sinica (植物生态学报), 26: $396 \sim 402$. (in Chinese with English abstract)

Tilman, D. \& J. A. Downing. 1994. Biodiversity and stability in grassland. Nature, 367: $363 \sim 365$.

Walker, B. H. 1992. Biological diversity and ecological redundancy. Conservation Biology, 6: $18 \sim 23$.

West, N. E. 1993. Biodiversity of rangelands. Journal of Range Management, 46: 2 13.

Wu, Y. (吴彦), Q. Liu (刘庆), Y. K. Qiao (乔永康), K. W. Pan (潘开文), C. M. Zhao (赵常明) \& Q. H. Chen (陈庆恒). 2001. Species diversity change in subalpine coniferous forests of different restoration stages and their effects on soil properties. Acta Phytoecologica Sinica (植物生态学报), 25: $648 \sim 655$. (in Chinese with English abstract)

Zhao, H. L. (赵哈林), X. Y. Zhao (赵学勇) \& T. H. Zhang (张铜会). 2000. Causes, processes and countermeasures of desertification in the interlocked agropasturing area of north China. Journal of Desert Research (中国沙漠), 20(Suppl. ) : 22 28 . (in Chinese with English abstract)

Zhao, P. (赵平) \& S. L. Peng (彭少麟). 2001. Species and species diversity in relation with restoration and persistence of degraded ecosystem function. Chinese Journal of Applied Ecology (应用生态学报), 12: 132 136. (in Chinese with English abstract) 